\section{SAT0164 MC2-03 (CICLOSPORIN EYEDROPS) IMPROVES TEAR PRODUCTION IN SJÖGREN'S PATIENTS WITH MODERATE-TO-SEVERE KERATITIS: RESULTS FROM A PHASE 2B RANDOMIZED, CONTROLLED TRIAL}

F. Gomez ${ }^{1}$, M. Præstegaard ${ }^{1}$, J. Selmer ${ }^{1}$, J. Horwath-Winter ${ }^{2}$, M. Sainz de la Maza $^{3}$, S. Heegaard ${ }^{4}{ }^{1} M C 2$ Therapeutics, Horsholm, Denmark; ${ }^{2}$ Department of Ophthalmology, Medical University, Graz, Graz, Austria; ${ }^{3}$ Clinical Institute of Ophthalmology, Hospital Clinic of Barcelona, Barcelona, Spain; ${ }^{4}$ Department of Ophthalmology/University Hospital Rigshospitalet, Copenhagen, Denmark

Background: Sjögren Syndrome (SS) is a multifaceted disease with variable symptoms, but the SS associated keratoconjunctivitis is one of the most frequent disease manifestations of the syndrome and the manifestation that has the greatest impact on the quality of life for these patients.

Objectives: To report the clinical efficacy of MC2-03 eyedrops in Sjögren's patients with moderate-to-severe keratitis from a 6-month trial looking at the Schirmer score which assess the tear production by the lacrimal gland. A Schirmer score of $\leq 5 \mathrm{~mm} / 5 \mathrm{~min}$ is one of the criteria used in the 2016 final classification of ACR/EULAR to diagnose Sjögren's syndrome.

Methods: The NORTHERN LIGHTS trial is a randomized, double masked, controlled multicentre European trial that assessed MC2-03 eyedrops (ciclosporin $0.03 \%$ and $0.06 \%$ ) for the treatment of moderate-to-severe dry eye disease in 255 patients having corneal fluorescein staining score 3 or 4 at baseline. The Schirmer score (per $5 \mathrm{~min}$ ) was assessed during this trial. A total of 66 patients $(25.9 \%)$ with medical history of Sjögren's syndrome were randomized in the trial.

Results: Demographics and baseline disease characteristics were comparable between treatment arms: mean age 60.4 years, $90.9 \%$ were females $(n=60)$ and the mean Schirmer score in the worst eye was $\sim 3 \mathrm{~mm}(2.8 \mathrm{~mm}-3.2 \mathrm{~mm}$, except for the vehicle, mean Schirmer score of $5.5 \mathrm{~mm}$ ).

The mean Schirmer score improved rapidly from baseline to month 1 for MC2$030.03 \%$ eye drops $(+2.4 \mathrm{~mm})$ reaching statistical significance versus vehicle $(-0.5 \mathrm{~mm}, \mathrm{p}=0.028)$ and lubricant therapy $(-0.6 \mathrm{~mm}, \mathrm{p}=0.020)$. This improvement was maintained at month 6 where the change was $+2.5 \mathrm{~mm}$ for MC2-03 $0.03 \%$ eye drops compared to $-1.1 \mathrm{~mm}$ for vehicle $(p=0.028)$. Statistical significance was also achieved at Month 6 comparing the higher strength MC2-03 $0.06 \%$ eye drops $(+2.8 \mathrm{~mm})$ to vehicle $(-1.1 \mathrm{~mm}, \mathrm{p}=0.005)$ and lubricant alone $(-0.5 \mathrm{~mm}$, $\mathrm{p}=0.009$ ).

Three in eleven $(27.3 \%)$ Sjögren's patients treated with MC2-03 $0.03 \%$ eye drops improved from a diagnostically low Schirmer $\leq 5 \mathrm{~mm}$ at baseline $(10 / 12$, $83.3 \% \leq 5 \mathrm{~mm})$ to Schirmer $>5 \mathrm{~mm}$ at month 3 and month $6(6 / 11,54.5 \% \leq 5 \mathrm{~mm})$, while on the other hand 1 in $14(7.1 \%)$ patients worsened in the vehicle group. A similar response was seen for MC2-03 eye drops $0.06 \%$.

For Sjögren's patients with Schirmer $\leq 5 \mathrm{~mm}$ at baseline, a greater proportion of patients improved $\geq 3 \mathrm{~mm}$ at month 6 when treated with MC2-03 eye drops $0.03 \%(44.4 \%, 4 / 9)$ and $0.06 \%(53.8 \%, 7 / 13)$ compared to vehicle $(0 \%$, $0 / 9)$ and lubricant $(7.7 \%, 1 / 12)$. At month 6 , a statistically significantly higher proportion of patients achieved clinically meaningful improvements in both corneal staining ( $\geq 2$ grades improvement) and Schirmer score $(\geq 3 \mathrm{~mm} / 5 \mathrm{~min})$ when treated with MC2-03 $0.03 \%$ eye drops $(45.5 \%, 5 / 11)$ compared to both vehicle $(0 \%, 0 / 14, p=0.009)$ and lubricant $(0 \%, 0 / 15, p=0.007)$. A higher number of patients treated with MC2-03 $0.06 \%$ was observed without statistical significance.

Conclusion: MC2-03 eye drops once daily rapidly increased tear production and further improved corneal staining in Sjögren's patients with moderate to severe keratitis, which both are objectives included as diagnostic criteria for Sjögren's disease. MC2-03 eye drops were well tolerated with no unexpected safety findings. Disclosure of Interests: : Frederic Gomez Consultant of: MC2 Therapeutics, Morten Præstegaard Employee of: MC2 Therapeutics, Johan Selmer Employee of: MC2 Therapeutics, Jutta Horwath-Winter Consultant of: CromaPharma, Omnivision, MC2 Therapeutics, Speakers bureau: Allergan, Bausch\&Lomb, Cromapharma, Ursapharma, Thea, TRB-Chemedica, Santen, Maite Sainz de la Maza: None declared, Steffen Heegaard Consultant of: Sanofi, MC2 Therapeutics, Speakers bureau: Santen, Sanofi, Thea, Leo

DOI: 10.1136/annrheumdis-2020-eular.1959

\section{SAT0165 \\ PRECLINICAL AND CLINICAL CHARACTERIZATION OF CENERIMOD, A POTENT, SELECTIVE, AND ORALLY ACTIVE SPHINGOSINE-1-PHOSPHATE RECEPTOR 1 MODULATOR IN SLE}

D. Strasser ${ }^{1}$, E. Gerossier ${ }^{1}$, V. Sippel ${ }^{1}$, U. Grieder ${ }^{1}$, A. Kieninger ${ }^{2}$, G. Pierlot ${ }^{1}$, H. Farine ${ }^{1}$, P. Kulig ${ }^{1}$, M. Keller ${ }^{1}$, S. Froidevaux ${ }^{1}$, M. Trendelenburg ${ }^{2}$, M. Martinic ${ }^{1}$,
M. Murphy ${ }^{1}{ }^{1}$ Idorsia Pharmaceuticals Ltd, Allschwil, Switzerland; ${ }^{2}$ University Hospital Basel, Basel, Switzerland

Background: SLE is an autoimmune disease characterized by aberrant lymphocyte activation and autoantibody production. In SLE, autoreactive lymphocytes migrate from lymphoid organs into the blood, and subsequently into tissue. This leads to systemic and multiorgan inflammation and pathology resulting in significant morbidity and mortality. Lymphocyte migration is a tightly controlled process driven by chemokine gradients. The chemotactic gradient across the vascular barrier established by sphingosine-1-phosphate (S1P) orchestrates egress of lymphocytes out of peripheral lymphoid organs into the blood. Cenerimod is a potent, selective, and orally active $\mathrm{S} 1 \mathrm{P}$ receptor $1\left(\mathrm{~S}_{1} \mathrm{P}_{1}\right)$ receptor modulator that induces receptor internalization and thereby prevents lymphocyte egress from lymphoid organs into the blood [1]

Objectives: In-depth preclinical and clinical characterization of cenerimod in modulating SLE.

Methods: Lymphocytes from patients with SLE and healthy subjects were assessed for cenerimod-induced $\mathrm{S}_{1} \mathrm{P}_{1}$ receptor internalization. Efficacy of cenerimod was evaluated in the MRL/lpr lupus mouse model. In a 12-week phase 2 clinical trial in patients with SLE treated with multiple doses of cenerimod (NCT02472795), lymphocyte subsets and inflammatory biomarkers were characterized.

Results: Cenerimod was potent and efficacious at inducing S1P, receptor internalization in $\mathrm{T}$ and $\mathrm{B}$ lymphocytes with an $\mathrm{EC}_{50}$ of $15 \mathrm{nM}$ in both healthy subjects and patients with SLE. In lupus-like MRL/Ipr mice treated with cenerimod, circulating $T$ and $B$ lymphocytes were reduced, which resulted in reduced immune infiltrates into tissue, reduced autoantibody production and inflammation decreased proteinuria, and increased survival. In patients with SLE treated with cenerimod for 12 weeks, a dose-dependent reduction of circulating T cells (95\%), B cells $(90 \%)$, and antibody-secreting cells $(85 \%)$ was evident. Furthermore, a reduction in anti-dsDNA antibodies and IFN-a, associated with an inflammatory phenotype, was observed.

Conclusion: Cenerimod was potent and efficacious in reducing $\mathrm{S}_{1} \mathrm{P}_{1}$ receptor surface expression on lymphocytes in vitro, and in reducing circulating $T$ and $B$ lymphocyte populations, including antibody-secreting cells, and in decreasing inflammatory biomarkers in patients with SLE in vivo. Furthermore, cenerimod significantly ameliorated systemic and organ-specific autoimmunity in a mouse model of SLE. These results support the further investigation of the clinical efficacy and safety of cenerimod in the ongoing phase $2 \mathrm{~b}$ clinical trial (NCT03742037).

References:

[1] Piali L, Birker-Robaczewska M, Lescop C, Froidevaux S, Schmitz N, Morrison $\mathrm{K}$, et al. Cenerimod, a novel selective S1P1 receptor modulator with unique signaling properties. Pharmacol Res Perspect. 2017 Dec; 5(6).

Acknowledgments: This research was funded by Idorsia Pharmaceuticals Ltd Disclosure of Interests: Daniel Strasser Shareholder of: Idorsia options/shares, Employee of: Idorsia employee, Estelle Gerossier Shareholder of: Idorsia options/ shares, Employee of: Idorsia employee, Virginie Sippel Shareholder of: Idorsia options/shares, Employee of: Idorsia employee, Ursula Grieder Shareholder of: Idorsia options/shares, Employee of: Idorsia, Andrea Kieninger: None declared Gabin Pierlot Shareholder of: Idorsia options/shares, Employee of: Idorsia employee, Hervé Farine Shareholder of: Idorsia options/shares, Employee of: Idorsia employee, Paulina Kulig Shareholder of: Idorsia options/shares, Employee of: Idorsia employee, Marcel Keller Shareholder of: Idorsia options/shares, Employee of: Idorsia employee, Sylvie Froidevaux Shareholder of: Idorsia options/shares, Employee of: Idorsia employee, Marten Trendelenburg Grant/research support from: Idorsia Pharmaceuticals Ltd, Novartis Institute of Biomedical Research, F. Hoffmann-La Roche Ltd, Marianne Martinic Shareholder of: Idorsia options/ shares, Employee of: Idorsia employee, Mark Murphy Shareholder of: Idorsia shares and stock options, Employee of: Idorsia employee DOI: 10.1136/annrheumdis-2020-eular.503

\section{SAT0166 BIOMARKERS OF B-CELL DEPLETION AND RESPONSE IN A RANDOMIZED, CONTROLLEDTRIAL OF OBINUTUZUMAB FOR PROLIFERATIVE LUPUS NEPHRITIS}

E. Vital ${ }^{1}$, P. Rémy ${ }^{2}$, L. F. Quintana Porras ${ }^{3}$, L. Chiche ${ }^{4}$, D. Chauveau ${ }^{5}$, R. Furie ${ }^{6}$, T. Schindler ${ }^{7}$, J. Garg ${ }^{8}$, M. D. Cascino ${ }^{8}$, Z. Amoura ${ }^{9}$, A. Doria ${ }^{10}$, C. M. D. Looney ${ }^{8}$, D. Roccatello ${ }^{11} .{ }^{1}$ Univ of Leeds, Leeds, United Kingdom; ${ }^{2}$ APHP Groupe Hospitalier Henri-Mondor, Créteil, France, ${ }^{3}$ Hospital Clinic de Barcelona, Barcelona, Spain; ${ }^{4}$ Hôpital Européen, Marseille, France; ${ }^{5}$ Hôpital Rangueil, Centre Hospitalier Univ de Toulouse, Toulouse, France; ${ }^{6}$ Northwell Health, Great Neck, NY, United States of America; ${ }^{7} \mathrm{~F}$ Hoffmann-La Roche Ltd, Basel, Switzerland: ${ }^{8}$ Genentech, Inc, South San Francisco, CA, United States 